\title{
UJIKUALITAS AIR PADA SUMBER MATA AIR WAIMARAPU DESA WAIMANU KECAMATAN KATIKUTANA SELATAN KABUPATEN SUMBA TENGAH
}

\author{
Eunike K. P. P. Ate, Yanti Daud, Merpiseldin Nitsae \\ Program Studi Pendidikan Biologi,Fakultas Keguruan dan Ilmu Pendidikan, Universitas \\ Kristen Artha Wacana Kupang- NTT \\ Coressponding Author:Kheke.ate@gmail.com
}

\begin{abstract}
ABSTRAK
Mata air Waimarapu merupakan sumber mata air di Desa Waimanu Kecamatan Katikutana Selatan Kabupaten Sumba Tengah. Masyarakat menggunakan mata air untuk mencukupi kebutuhan air bersih (sebagai air minum, mandi, cuci, dan pengairan tanaman) akan tetapi belum mengetahui kualitas air tesebut. Tujuan dalam penelitian ini adalah untuk mempelajari kualitas dari mata air Waimarapu dengan acuan Peraturan Pemerintah Nomor 82 Tahun 2001. Metode penelitian yang digunakan adalah metode eksperimen dan dianalisis secara deskriptif kuantitatif dengan membandingkan data hasil pengukuran dari masing-masing parameter air dengan nilai baku mutu Peraturan Pemerintah Nomor 82 Tahun 2001. Berdasarkan hasil penelitian yang dilakukan ada 3 parameter yang tidak sesuai dengan baku mutu yaitu kandungan oksigen terlarut $(5,60 \mathrm{mg} / \mathrm{L})$ tembaga $(0,11 \mathrm{mg} / \mathrm{L})$ dan phospat $(0,54 \mathrm{mg} / \mathrm{L})$. Hal ini disebabkan oleh karena perubahan cuaca, pergerakan massa air dan lokasi mata air Waimarapu yang berada di area persawahan sehingga menyebabkan masuknya limbah pertanian (penggunaan pupuk dan pembasmi hama). Sedangkan untuk parameter lainnya (suhu, TDS, TSS, pH, BOD, besi, mangan, sulfat, nitrat, nitrit, klorin, sianida, dan total coliform) masih sesuai dengan baku mutu yang ditetapkan. Nilai ini masih bisa ditolerir dalam kualitas air. Berdasarkan hasil yang diperoleh, mata air Waimarapu masih berada dalam batas aman untuk digunakan sesuai peruntukkannya.
\end{abstract}

Kata Kunci : Kualitas Air, Mata Air Waimarapu, Kadar Tembaga dan Phospat

\begin{abstract}
The Waimarapu springs is located in Waimanu Village, South Katikutana District, Central Sumba Regency. People usually use springs for their necessary (such as drinking water, bathing, washing, and irrigation plants) but does not know the quality of the water. The purpose of this study was to determine the quality of the Waimarapu spring with reference to Government Regulation No. 82 of 2001 . The research method used was an experimental method and analyzed quantitatively by comparing the measurement data of each water parameter with the quality standard of Government Regulation Number 82 of 2001. Based on the results of the research, there were 3 parameters that were not in accordance with the quality standards, namely dissolved oxygen content $(5.60 \mathrm{mg} / \mathrm{L})$ of copper $(0.11 \mathrm{mg} / \mathrm{L})$ and phosphate $(0.54 \mathrm{mg} / \mathrm{L})$. This is caused by changes in weather, the movement of the water mass and the location of Waimarapu springs in the rice fields, which causes the entry of agricultural waste (use of fertilizers and pest control). Whereas for other parameters (temperature, TDS, TSS, $\mathrm{pH}, \mathrm{BOD}$, iron, manganese, sulfate, nitrate, nitrite, chlorine, cyanide and total coliform) are still in accordance with the established quality standards. This value can still be tolerated in water quality. Based on the results obtained, the Waimarapu spring is still within safe limits to be used according to its designation.
\end{abstract}

Keywords: Water Quality, Waimarapu Spring, Copper Content and Phosphates 


\section{PENDAHULUAN}

Air merupakan salah satu sumber daya alam dan bagian dari kehidupan yang fungsinya tidak dapat digantikan oleh senyawa lain, sehingga wajib untuk diketahui kandungan air baik kualitas dan kuantitasnya. Kehadiran air menopang kehidupan semua makhluk hidup. Air bersih memenuhi syarat kesehatan harus bebas dari pencemaran, sedangkan air minum harus memenuhi standar yaitu persyaratan fisik, kimia dan biologis karena air minum yang tidak memenuhi standar kualitas dapat menimbulkan gangguan kesehatan (Morintoh dkk, 2015).

Menurut Peraturan Pemerintah No. 82 Tahun 2001, mutu air adalah kondisi kualitas air yang diukur atau diuji berdasarkan parameter-parameter dan metode tertentu berdasarkan peraturan perundang-undangan yang berlaku. Pemanfaatan air untuk berbagai kebutuhan harus memperhatikan parameter- parameter kualitas air sesuai baku mutu yang ditetapkan. Seperti pemenuhan kebutuhan masyarakat sehari-hari di Desa Waimanu Kecamatan Katikutana Selatan Kabupaten Sumba Tengah.

Kecamatan Katikutana Selatan merupakan salah satu Kecamatan yang ada di Kabupaten Sumba Tengah dan memiliki beberapa mata air yang digunakan masyarakat untuk mencukupi kebutuhan, salah satunya ialah mata air Waimarapu yang terletak di Desa Waimanu dan merupakan sumber mata air yang digunakan oleh masyarakat untuk mencukupi kebutuhan air bersih. Mata air Waimarapu berada di daerah persawahan dan memiliki 1 aliran air yang digunakan oleh masyarakat untuk mandi, cuci dan pengairan tanaman, sedangkan untuk minum masyarakat mengambil langsung pada mata airnya. Jarak yang harus ditempuh oleh masyarakat untuk sampai ke mata air ini $\pm 1 \mathrm{~km}$. Masuknya bahan pencemar (polutan) seperti limbah cair domestik, dan limbah pertanian kedalam mata air akan mempengaruhi kualitas dari mata air tersebut, perubahan musim kemarau dan musim hujan, kondisi lingkungan sekitar, dan tingkah laku manusia.

\section{METODE PENELITIAN}

\section{Alat dan Bahan}

Sampel air dari Mata Air Waimarapu, aqua bidestilata steril (aquades), air suling, alkohol, pereaksi standard yang mempunyai tingkat kemurnian yang tinggi untuk menentukan ion-ion dalam sampel air, media Lactase Bouillon (LTB), media Brilliant Green Lactase Bilebroth (BGLB), oven, inkubator, autoclave, spektofotometer, pompa vacuum, hotplate stirer, cyberscan PCD 650, GPS, box, timbangan analitik, vortex, rak tabung reaksi, botol sampel, beker gelas, erlenmeyer, kuvet, pipet volum $10 \mathrm{ml}$ dan $5 \mathrm{ml}$, tabung reaksi, penjepit, jarum ose, bunsen, cawan petri, kaca arloji, kertas saring 5,5 $\mu \mathrm{m}$, spatula, tabung durham, gunting, kapas, tisu, kertas label, korek api.

\section{Metode Pengujian}

Penelitian ini dibatasi pada pengujian 3 parameter yaitu: Parameter Fisika (Temperatur, TDS dan TSS) Parameter Kimia (pH, DO, BOD, Besi, Mangan, Sulfat, Nitrat, Nitrit, Khlorin, Sianida, Tembaga, dan Phospat) 'Parameter Mikrobiologi (total Coliform). Pengujian menggunakan metode eksperimen dan dianalisis secara deskriptif kuantitatif. Metode pengujiannya disajikan dalam Tabel 1: 
Tabel 1. Metode pengujian kualitas air

\begin{tabular}{|c|c|c|}
\hline No & Parameter & Metode Pengujian \\
\hline & & FISIKA \\
\hline 1 & Suhu & SNI 06-6989.23-2005 \\
\hline 2 & Residu Terlarut (TDS) & SNI 06-6989.27-2005 \\
\hline 3 & Tersuspensi & SNI 06-6989.3-2004 \\
\hline & & KIMIA \\
\hline 4 & $\mathrm{pH}$ & SNI 06-6989.11-2004 \\
\hline 5 & DO & $\begin{array}{l}\text { Stick Probe/Hach Method } 8166 \text { Accuvac } \\
\text { Ampul }\end{array}$ \\
\hline 6 & BOD & $\begin{array}{l}\text { Stick Probe/Hach Method } 8166 \text { Accuvac } \\
\text { Ampul }\end{array}$ \\
\hline 7 & Besi (Fe) & Hach Method 8146Powder Pillow \\
\hline 8 & Tembaga $(\mathrm{Cu})$ & Hach Method 8506 Powder Pillow \\
\hline 9 & Nitrit sebagai $\mathrm{N}$ & Hach Method 8507 Powder Pillow \\
\hline 10 & NO3 sebagai $\mathrm{N}$ & Hach Method 8039 Powder Pillow \\
\hline 11 & Sianida & Hach Method 8027 Powder Pillow \\
\hline 12 & Mangan & Hach Method 8149 Powder Pillow \\
\hline 13 & Phospat $(\mathrm{P})$ & Hach Method 8048 Powder Pillow \\
\hline 14 & Khlorin & Hach Method 8021 Powder Pillow \\
\hline$\overline{15}$ & Sulfat & Hach Method 8051 Powder Pillow \\
\hline & & MIKROBIOLOGI \\
\hline 16 & Total coliform & $\begin{array}{l}\text { Standard Methods for The Examination of } \\
\text { Water and Wastewater }\end{array}$ \\
\hline
\end{tabular}

\section{HASIL DAN PEMBAHASAN}

Adapun hasil yang diperoleh dari pengujian kualitas air Waimarapu Desa Waimanu yang dibandingkan dengan Baku Mutu Peraturan Pemerintah Nomor 82 Tahun 2001 ditampilkan dalam Tabel 2:

Hasil penngujian kaulitas air pada parameter fisika, kimia dan biologi dibahas sebagai berikut :

\section{a. Suhu}

Suhu air dipengaruhi oleh radiasi cahaya matahari, suhu udara, cuaca dan lokasi. Pada suhu air yang hangat, kapasitas oksigen terlarutnya berkurang. Hal ini disebabkan oleh karena cuaca yang terjadi di lokasi penelitian ketika melakukan pengukuran suhu adalah berawan.

b. TDS

Pengukuran TDS dilakukan untuk mengukur banyaknya zat padat total pada sampel dalam satuan $\mathrm{mg} / \mathrm{L}$. Padatan terlarut alami berasal dari pelapukan batuan dan tanah.

c. TSS

Padatan tersuspensi berasal dari tanah liat, bahan organik tertentu dan sel-sel mikroorganisme. Sedangkan mata air Waimarapu memiliki dasar yang tidak berlumpur dan berpasir.

\section{d. $\mathrm{pH}$}

Nilai $\mathrm{pH}$ mengindikasikan apakah air tersebut netral, asam, atau basa. Air dengan $\mathrm{pH}$ dibawah 7 termasuk asam dan diatas 7 termasuk basa. Hasil pengukuran $\mathrm{pH}$ mata air Waimarapu masih tergolong normal. Mata air yang muncul di sekitar daerah kapur umumnya mempunyai pH yang relatif tinggi (Sudarmadji, 2012).

e. DO

Hasil pengukuran DO yang diperoleh pada mata air Waimarapu adalah menunjukkan hasil belum memenuhi standar baku mutu kelas I. Hal ini disebabkan oleh karena perubahan cuaca dan pergerakan massa air dan banyaknya lumut yang hidup di dasar mata air. Kecepatan difusi oksigen dari udara, tergantung dari beberapa faktor, seperti kekeruhan air, kedalaman dan pergerakan massa air (Salmin, 2005). 
Tabel 2 Hasil yang diperoleh dari pengujian kualitas air Waimarapu Desa Waimanu

\begin{tabular}{llccc}
\hline No & Parameter & Satuan & Hasil & $\begin{array}{c}\text { Baku Mutu PP No. 82 } \\
\text { Tahun 2001 Kelas.l }\end{array}$ \\
\hline \multicolumn{4}{c}{ FISIKA } \\
\hline a & Temperatur & ${ }^{\circ} \mathrm{C}$ & 25 & $\pm 3^{\circ} \mathrm{C}$ \\
\hline b & $\begin{array}{l}\text { Residu } \\
\text { Terlarut (TDS) }\end{array}$ & $\mathrm{mg} / \mathrm{L}$ & 215 & 1000 \\
\hline C & Residu Tersuspensi (TSS) & $\mathrm{mg} / \mathrm{L}$ & 0,001 & 50
\end{tabular}

\begin{tabular}{|c|c|c|c|c|}
\hline \multicolumn{5}{|c|}{ KIMIA } \\
\hline $\mathrm{d}$ & $\mathrm{pH}$ & $\mathrm{mg} / \mathrm{L}$ & 7,36 & $6-9$ \\
\hline $\bar{e}$ & $\mathrm{DO}$ & $\mathrm{mg} / \mathrm{L}$ & $5,60^{\star \star}$ & 6 \\
\hline$f$ & BOD & $\mathrm{mg} / \mathrm{L}$ & 1,88 & 2 \\
\hline$g$ & Besi (Fe) & $\mathrm{mg} / \mathrm{L}$ & 0,03 & 0,3 \\
\hline $\mathrm{h}$ & Tembaga $(\mathrm{Cu})$ & $\mathrm{mg} / \mathrm{L}$ & $0,11^{*}$ & 0,02 \\
\hline $\mathrm{i}$ & $\begin{array}{l}\text { Nitrit sebagai } \\
\mathrm{N}\end{array}$ & $\mathrm{mg} / \mathrm{L}$ & 0,004 & 0,06 \\
\hline j & $\mathrm{NO}_{3}$ sebagai $\mathrm{N}$ & $\mathrm{mg} / \mathrm{L}$ & 1,0 & 10 \\
\hline $\mathrm{k}$ & Sianida (CN) & $\mathrm{mg} / \mathrm{L}$ & 0,002 & 0,02 \\
\hline $\mathrm{I}$ & Mangan & $\mathrm{mg} / \mathrm{L}$ & 0,029 & 0,1 \\
\hline $\mathrm{m}$ & Total Phospat sebagai $\mathrm{P}$ & $\mathrm{mg} / \mathrm{L}$ & $0,54^{*}$ & 0,2 \\
\hline $\mathrm{n}$ & Khlorin Bebas & $\mathrm{mg} / \mathrm{L}$ & 0,00 & 0,03 \\
\hline 0 & Sulfat & $\mathrm{mg} / \mathrm{L}$ & 0,00 & 400 \\
\hline$p$ & Total coliform & $\mathrm{Jm}$ & 5,5 & 1000 \\
\hline
\end{tabular}

Keterangan :

$\left.{ }^{*}\right)$ : Melebihi baku mutu

$\left.{ }^{\star *}\right)$ : Belum memenuhi baku mutu

\section{f. BOD}

BOD secara umum dipakai untuk menentukan tingkat pencemaran air buangan. Jika kadar BOD yang dimiliki lebih kecil, hal ini mengindikasikan bahwa air tersebut belum tercemar oleh bahan organik seperti tumbuhan atau hewan yang sudah mengalami pembusukan.

\section{g. Besi}

Besi dapat larut pada $\mathrm{pH}$ yang rendah, dan akan membawa dampak buruk jika dikonsumsi dalam jumlah yang banyak dan melebihi batas baku mutu.

\section{h. Tembaga}

Hasil tembaga ( $\mathrm{Cu}$ ) yang diperoleh pada mata air Waimarapu melebihi batas baku mutu. Naiknya kandungan tembaga pada air tersebut disebabkan oleh karena pembuangan limbah pertanian, utamanya sisa-sisa penggunaan pestisida. Toksisitas yang dimiliki oleh tembaga baru akan bekerja dan memperlihatkan pengaruhnya bila logam ini telah masuk ke dalam tubuh organisme dalam jumlah yang besar (Sekarwati, 2015).

\section{i. Nitrit}


Nitrit di perairan alami berkadar sangat kecil dan lebih sedikit daripada nitrat karena segera dioksidasi menjadi nitrat. Sumber nitrit dapat berupa limbah domestik kotoran hewan yang berada di sekitar mata air. 


\section{j. Nitrat}

Nitrat sangat mudah larut dalam air dan stabil. Nitrat merupakan nutrient yang dapat mempercepat pertumbuhan organisme juga dapat menurunkan konsentrasi oksigen terlarut di dalam perairan.

\section{k. Sianida}

Kehadiran sianida dikategorikan sebagai bahan beracun dan berbahaya. Mata air Waimarapu belum tercemar oleh sianida dikarenakan sianida yang terkandung tidak melebihi batas baku mutu, dan masih tergolong aman untuk dikonsumsi.

\section{Mangan}

Mangan secara alami banyak terjadi pada air permukaan dan air tanah dan dapat berikatan dengan nitrat, sulfat, klorida dan larut dalam air.

\section{m. Phospat}

Hasil pengukuran Phospat (PO4-) yang diperoleh pada mata air Waimarapu melebihi batas baku mutu. Phospat banyak berasal dari bahan pembersih dan juga sumber pupuk yang dapat meningkatkan produktivitas tanah dan tanaman (Rahadi, 2012). ). Kandungan phospat yang tinggi dalam perairan juga dapat menyebabkan suburnya organisme lainnya, seperti lumut yang terletak di dasar perairan.

\section{n. Klorin bebas}

Sumber klorida dalam air tanah dapat terjadi secara alami dan akibat kegiatan manusia seperti air limpasan, penggunaan pupuk anorganik, air lindi dari persampahan, dan pakan ternak. klorin bersifat menguap sehingga tidak di temukan unsur klorin dalam air.

\section{o. Sulfat}

Kehadiran sulfat dapat menimbulkan masalah bau dan korosi. Sampel mata air yang mengandung sulfat dalam kadar yang rendah dan normal dalam kisaran sebagai air tawar alami menunjukkan belum terjadi pencemaran oleh aktivitas pertanian.

\section{p. Total coliform}

Bakteri coliform dapat bersumber dari limbah, limpasan pertanian,kontaminasi dengan tinja dan lainnya (Sulistyorini, 2016). Kehadiran bakteri coliform menunjukkan bahwa terdapat hubungan yang erat diantara aktivitas manusia dengan kehadiran dan kandungan bakteri pencemar. Semakin kecil kandungan total coliform maka akan semakin sedikit adanya bakteri patogenik yang terkandung di dalam air tersebut. Hasil pengujian total coliform (Gambar 1) yang diperoleh pada Mata Air Waimarapu tidak melebihi ambang batas yang telah ditetapkan sehingga air tersebut dapat dimanfaatkan sesuai peruntukannya.

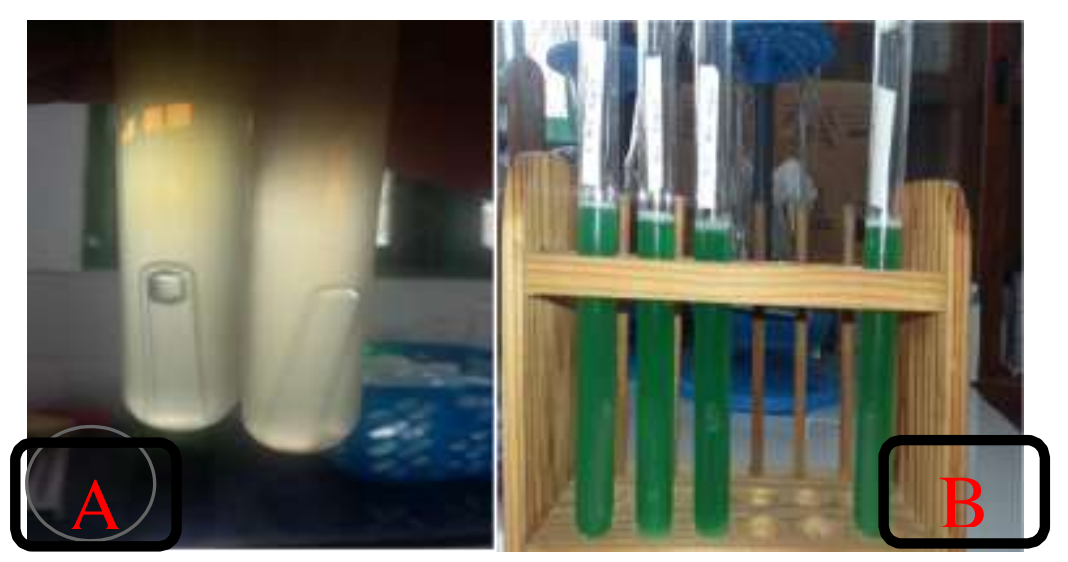

Gambar 1. a. Pendugaan bakteri coliform b. Penguat adanya bakteri coliform (Sumber : penulis, 2017) 


\section{Simpulan}

\section{PENUTUP}

Berdasarkan hasil uji kualitas air pada Mata Air Waimarapu, dengan membandingkan data hasil pengujian dari masing-masing parameter dengan nilai baku mutu Peraturan Pemerintah Nomor 82 Tahun 2001 dapat disimpulkan bahwa dari 16 indikator yang memenuhi baku mutu adalah Suhu, TDS, TSS, pH, BOD, Besi, Mangan, Sulfat, Nitrat, Nitrit, Klorin, Sianida, dan Total coliform. Sedangkan parameter yang memiliki nilai tidak sesuai dengan baku mutu adalah oksigen terlarut (DO), Tembaga dan Phospat.

\section{Saran}

1. Penelitian ini dapat dijadikan referensi mengenai kualitas air di mata air Waimarapu Kabupaten Sumba Tengah.

2. Pengelolaan kualitas air perlu diperhatikan oleh masyarakat dan pihak terkait sehingga Mata Air Waimarapu tetap terjaga kualitasnya, dan tidak memberikan dampak kesehatan yang buruk bagi masyarakat.

3. Sebaiknya untuk parameter lapangan seperti pengukuran DOO dilakukan langsung di lapangan karena dapat berpengaruh terhadap hasil pengukuran.

4. Sebaiknya untuk setiap parameter perlu dilakukan pengulangan, sehingga memperoleh hasil yang lebih akurat.

\section{DAFTAR PUSTAKA}

Morintoh, P, Jimmy F. Rumampuk, Fransiska Lintung. 2015. Analisis Perbedaan Uji Kualitas Air Sumur di Daerah Dataran Tinggi Kota Tomohon dan Dataran Rendah Kota Manado Berdasarkan Parameter Fisika. Jurnal e- Biomedik (eBm), Vol 2 No.1

Rahadi, B, Novia Lusiana. 2012. Penentuan Kualitas Air Tanah Dangkal dan

Arahan Pengelolaan. Jurnal Teknologi Pertanian Vol 13 No.2

Salmin, 2005. Oksigen Terlarut (DO) dan Kebutuhan Oksigen Biologi (BOD) sebagai salah satu indikator untuk mnentukan kualitas pertanian. Oseana, Vol XXX No.3

Sekarwati Novita, Bardi Murachman dan Sunarto. 2015. Dampak Logam Berat Cu (Tembaga) dan Ag (Perak) Pada Limbah Cair Industri Perak Terhadap Kualitas Air Sumur dan Kesehatan Masyarakat serta Upaya Pengendaliannya di Kota Gede Yogyakarta. Jurnal EKOSAINS Vol VII No.1

Sudarmadji, 2012. Mata Air Perspektif Hidrologis Dan Lingkungan, Yogyakarta:UGM

Sulistyorini, I, S. Muli Edwin dan Adriana Sampe Arung. 2016. Analisis Kualitas Air Pada Sumber Mata Air di Kecamatan Karangan dan Kaliorang Kabupaten Kutai Timur. Jurnal Hutan Tropis, Vol 14 No.1 